\title{
Induction of Neonatal Tolerance to Oxidized Lipoprotein Reduces Atherosclerosis In ApoE Knockout Mice
}

\author{
Antonino Nicoletti ${ }^{* 1,2}$, Gabrielle Paulsson ${ }^{* 1}$, Giuseppina Caligiuri ${ }^{1}$, \\ Xinghua Zhou ${ }^{1}$, Göran K. Hansson ${ }^{1}$ \\ ${ }^{1}$ Center for Molecular Medicine, Karolinska Institute, Stockholm, Sweden \\ ${ }^{2}$ INSERM U430, Hôpital Broussais, Paris, France
}

Communicated by H. Wigzell. Accepted January 28, 2000.

\begin{abstract}
Background: In the course of atherosclerosis, humans and apolipoprotein (apoE) Knockout (KO) mice exhibit an active cell-mediated and humoral immune process, both at the systemic level and within atheromata. Low density lipoproteins (LDL) infiltrate the vascular wall, where they are oxidatively modified. This oxidative modification may generate new epitopes for which tolerance is not achieved during ontogenesis. Such epitopes could constitute new targets for autoreactive immune responses that may have a physiopathological role in disease development.

Materials and Methods: Exposing mice to high dose of antigens during thymic T-cell education induces immunological tolerance to the administered antigens. We injected newborn apoE KO mice with oxidized
\end{abstract}

LDL. They were fed a cholesterol-rich diet and aortic atherosclerosis, cell-mediated immune response, and T-cell repertoire were analyzed after 5 months.

Results: Injection of oxidized LDL at birth reduced not only the immune response to oxidized LDL, but also susceptibility to atherosclerosis in apoE mice. Injection of oxidized LDL induced T-cell tolerance due to clonal deletion, rather than anergy of the reactive $\mathrm{T}$ cells. The T-cell repertoire of apoE $\mathrm{KO}$ mice was affected by the development of the disease, whereas tolerization normalized it.

Conclusions: This study demonstrates that the immune response against oxidized LDL has a deleterious role in atherogenesis and that a fine-tuning of this response could modify the course of the disease.

\section{Introduction}

Atherosclerotic cardiovascular disease, the major cause of morbidity and mortality, is characterized by progressive obstruction of blood vessels due to cellular and extracellular deposits in the arterial wall. The recently developed apolipoprotein (apoE) knockout (KO) mouse $(1,2)$ provides an excellent experimental model to study this disease. Both humans and the apoE KO mice exhibit an active cellmediated (3-5) and humoral (6,7) immune process within atheromata. Low density lipoproteins (LDL) infiltrate the vascular wall

*Contributed equally to the work.

Address correspondence and reprint requests to: Dr. Göran K. Hansson, Center for Molecular Medicine L8:03, Karolinska Hospital, S-17176 Stockholm, Sweden. Fax

+46-8-313147; E-mail Goran.Hansson@cmm.ki.se where they are modified by peroxidation of the lipid portion, which leads to release of free aldehydes like malondialdehydes and 4hydroxynonenal (8). These may react with the protein portion of LDL, apolipoprotein B-100. We previously showed that oxidation was targeting LDL to scavenger receptor type Adependent antigen presentation (9). T-cell clones recognizing oxidized LDL (oxLDL) are present in apoE KO mice (10). Nevertheless, the existence of an immune response directed against newly oxidatively generated epitopes does not imply its functional role in disease progression. Therefore, we tried to modify the specific spontaneous immune reactivity towards oxLDL in apoE $\mathrm{KO}$ mice by inducing tolerance to oxLDL and evaluated its effects on atherosclerosis.

The absence of responses to self-components that $T$ cells can encounter can be ex- 
plained by several mechanisms. First, $\mathrm{T}$ cells reactive to self-antigens would be rendered anergic, for instance, due to antigen presentation in the absence of co-stimulatory signals, or held in check by T-suppressor cells. Second, neonatal "tolerization" could induce immune deviation. Neonates would not be immuneprivileged, but would generate Th2 or Th1 responses, depending on the mode of immunization (11). Last, T cells with potential reactivity for nonsequestered self antigens would be deleted as a result of exposition to these antigens at high concentration early in ontogeny. Atherosclerosis is associated with the presence of autoreactive clones specific for modified LDL $(5,12)$. Such T-cell clones apparently escape deletion during the negative thymic selection, probably because the concentration of oxLDL is very low. To evaluate the effect of tolerization towards oxLDL on atherosclerosis, we injected newborn apoE KO mice with oxLDL. After 3 months on a Western diet, tolerized mice showed a significantly decreased immune reactivity towards oxLDL and a decreased susceptibility to atherosclerosis. These results suggest that the cellular immune response directed against oxLDL accelerates the disease.

\section{Materials and Methods}

\section{Experimental Protocol}

Pregnant ApoE KO mice (M\&B, Bomholtgaard, Denmark) delivered in our animal facility. Within the first $24 \mathrm{hr}$ of life, the pups were intraperitonally injected with 60 to $80 \mu \mathrm{g}$ of oxLDL or phosphate-buffered saline (PBS) as control. At 5 weeks of age, apoE KO mice were placed on a $0.15 \%$ cholesterol "Western" diet (AB AnalyCen, Linköping, Sweden). Data presented are from one of three different experiments ( $n=10 \mathrm{mice} /$ group). Totally, 35 male and female mice were used as controls and 33 male and female mice received oxLDL.

\section{LDL Preparations}

Human LDL ( $\mathrm{d}=1.019-1.063 \mathrm{~g} / \mathrm{ml})$ was obtained under sterile conditions by ultracentrifugation of human plasma collected from 10 donors. Malondialdehyde (MDA) modified and oxLDL were produced as previously described $(10,13,14)$. The titers of immunoglobulin $G$ ( $\operatorname{Ig} G)$ and immunoglobulin $M$ (IgM) serum autoantibodies directed against LDL,
MDA-LDL and oxLDL were measured by ELISA [15].

\section{Tissue Processing}

At sacrifice, blood was collected and serum separated. The cholesterol concentration was assessed using a Unimate kit (Hoffman-La Roche, Basel, Switzterland) and a Cobas Mira analytical system (Hoffman-La Roche). Spleen and lymph nodes (LN) were harvested for in vitro assay, fluorescence-activated cell sorting (FACS) and reverse transcription-polymerase chain reaction (RT-PCR). The aorta was dissected under a macroscope and snap-frozen in (OCT) for serial cryosectioning covering $0.8 \mathrm{~mm}$ of the root. The first section was harvested when the first cusp became visible in the lumen of the aorta. Five sections of $10 \mu \mathrm{m}$ in thickness were harvested per slide and, thus, 18 slides per mouse were prepared. Sections at $0,200,400,600$, and $800 \mu \mathrm{m}$ distance from the cusps were stained with oil red $O$ (10). Cryosections were also processed for immunohistochemistry as described $(3,10)$ using CD4 (1:50), CD8 (1:50) and I-A $\mathrm{A}^{\mathrm{b}}(1: 25)$ antibodies (PharMingen, San Diego, CA). All sections were counterstained with haematoxylin.

\section{Quantitation of Atherosclerotic Lesions}

The oil red $\mathrm{O}$-stained cryosections were analyzed at $5 \times$ magnification. The image was captured on a microcomputer and a program developed in Quips language (Leica, Cambridge, U.K.) permitted a quantitation of the crosssection surface area of the lesion and the crosssection surface area of the vessel. The ratio of these two areas provided the fraction area of the lesion (10).

\section{Cell Culture}

LN cells and spleen cells were prepared by meshing the tissues on $100 \mu \mathrm{m}$ nylon filters, followed by a series of washing steps in Dulbecco's modified Eagle's medium with 5\% fetal bovine serum (DMEM-5\%). Red blood cells were lysed in the spleen cell preparations. 300,000 cells/well were plated in triplicate in the presence of the following stimuli: Concanavalin A (Sigma, St. Louis, MO), ox- and native LDL. Cell proliferation was assessed by the incorporation of ${ }^{3} \mathrm{H}$-thymidine in 6-day assays. 


\section{FACS Analysis}

A fraction of the cells prepared for culture was used for FACS analysis to check the different cell populations. Cells were stained for $20 \mathrm{~min}$ at $4^{\circ} \mathrm{C}$ using fluorescent-conjugated antibodies directed to CD69 (FITC), CD3 (FITC), CD 19 (PE), CD4 (Cy), CD8 (PE) (Pharmingen, San Diego, CA, USA). Cells were washed and analyzed with a FACSCalibur ${ }^{\circledR}$ (Becton Dickinson, Mountain View, CA) flow cytometer.

\section{T-cell Repertoire Analysis}

RBA AND CDNA PREPARATIONS. RNA was prepared from $2 \times 10^{6}$ cells (RNeasy, Qiagen). Singlestranded cDNA synthesis was performed by Superscript II (Life Technologies, Täby, Sweden), according to the manufacturer and using random pdN6 as primers (Pharmacia, Uppsala, Sweden).

LeNGTH ANALYSIS OF THE CDR3 RegION. Amplification of cDNA was done by polymerase chain reaction (PCR). Each reaction contained $1 \mu \mathrm{l}$ cDNA, $10 \mathrm{mM}$ Tris- $\mathrm{HCl}, 50 \mathrm{mM} \mathrm{KCl}$ (Life Technologies), $1.5 \mathrm{mM} \mathrm{MgCl}_{2}$ (Life Technologies), $1 \mathrm{mM}$ each $\mathrm{dNTP}, 0.2 \mathrm{U} / \mathrm{ml}$ Taq DNA Polymerase (Life Technologies), $1 \mu \mathrm{l} \mathrm{C} \beta$ 3'primer $(10$ pmole/ml $)$ labeled with fluorochrome FAM (GENSET, Paris, France), $1 \mu \mathrm{l}$ $\mathrm{V} \beta 5^{\prime}$-primer ( $\left.10 \mathrm{pmole} / \mathrm{ml}\right)$. Primer sequences were derived as previously described (16-23).
PCR products were analyzed on high-resolving polyacrylamide gel electrophoresis (PAGE) in an ABI Automatic Sequencer (Perkin-Elmer Foster City, CA). Data were analyzed with the software Genotyper 2.0 (ABI, Perkin-Elmer).

\section{Statistical Analysis}

Results are expressed as means \pm SEM. Data were analyzed by one- and two-factor analysis of variance (ANOVA), and Mann-Whitney non-parametric tests using Statview 5.0 software (SAS Institute Inc, Cary, NC). Differences between groups were considered significant if $p<0.05$.

\section{Results and Discussion}

ApoE KO mice were treated during the first 24 hr of life with a single, intraperitoneal injection of copper-oxidized LDL. Generally, neonatal tolerance to protein or peptides is performed by emulsifying them in incomplete Freund adjuvant (IFA). In our case, injection of the genuine protein was preferred, because IFA creates a bias towards a Th2 immune response (11), which could influence the progression of the disease. OxLDL as a tolerogen was expected to be present throughout the entire life of the apoE KO mice, thus, exerting a constant nega-

Table 1. Effect of tolerization on physiologic parameters, immunoglobulin G (IgG) and immunoglobulin $M$ (IgM) autoantibody titers assessed by ELISA, and cell populations assessed by FACS analysis (means \pm SEM)

\begin{tabular}{|c|c|c|c|c|}
\hline \multirow{2}{*}{$\begin{array}{l}\text { Weight (g) } \\
\text { Cholesterol (mmol/L) }\end{array}$} & \multicolumn{2}{|c|}{ Male } & \multicolumn{2}{|c|}{ Female } \\
\hline & Control & Tolerized & Control & Tolerized \\
\hline Weight (g) & $33.4 \pm 1.50$ & $32.8 \pm 1.30$ & $25.3 \pm 1.30$ & $26.3 \pm 0.90$ \\
\hline Cholesterol $(\mathrm{mmol} / \mathrm{L})$ & $1.58 \pm 0.27$ & $1.39 \pm 0.27$ & $1.30 \pm 0.06$ & $1.27 \pm 0.30$ \\
\hline ox-LDL & $1.39 \pm 0.06$ & $1.32 \pm 0.03$ & $1.50 \pm 0.08$ & $1.51 \pm 0.05$ \\
\hline MDA-LDL & $3.09 \pm 0.16$ & $2.78 \pm 0.30$ & $2.79 \pm 0.21$ & $2.69 \pm 0.02$ \\
\hline ox-LDL & $1.11 \pm 0.10$ & $1.08 \pm 0.05$ & $1.19 \pm 0.04$ & $1.12 \pm 0.02$ \\
\hline MDA-LDL & $2.30 \pm 0.18$ & $2.10 \pm 0.26$ & $2.87 \pm 0.28$ & $2.20 \pm 0.49$ \\
\hline $\mathrm{CD}{ }^{+}$ & $37 \pm 2$ & $40 \pm 3$ & $39 \pm 2$ & $41 \pm 2$ \\
\hline $\mathrm{CD}^{+}$ & $55 \pm 2$ & $52 \pm 4$ & $55 \pm 2$ & $53 \pm 1$ \\
\hline $\mathrm{CD4}^{+}$ & $52 \pm 2$ & $51 \pm 2$ & $45 \pm 2$ & $51 \pm 2$ \\
\hline $\mathrm{CD8}^{+}$ & $39 \pm 2$ & $40 \pm 2$ & $43 \pm 2$ & $37 \pm 4$ \\
\hline $\mathrm{CD}^{+} 9^{+}$ & $4.7 \pm 0.2$ & $4.8 \pm 0.5$ & $4.0 \pm 0.2$ & $4.1 \pm 0.8$ \\
\hline
\end{tabular}

MDA-LDL, malondialdehyde-low density lipoproteins; ox-LDL, oxidized low density lipoproteins. 
tive selection pressure and the injections were, therefore, not repeated. Control mice from the same litter received PBS injections. At 5 weeks of age, mice were placed on a "Western" diet containing $0.15 \%$ cholesterol to increase lipoprotein levels and accelerate the formation of atherosclerotic lesions. Mice were sacrificed after 4 months of diet. As expected, the weight and the cholesterol level of male mice exceeded those of females; the injection of oxLDL did not modify these values significantly (Table 1).

The precise T-cell epitope(s) on oxLDL remain unclear. We, therefore, used copper-oxidized LDL as a tolerogen, since this preparation results in a large number of different chemical modifications of the LDL particle (8). However, this type of oxidation may eventually destroy certain components of the particle and it will be important to identify T-cell epitopes and use structurally defined preparations of those in future experiments.

The extent of lesion development was assessed in the root of the aorta. As shown in Figure 1, tolerized mice exhibited significantly smaller lesions than control mice. Female mice presented bigger lesions than male mice, which was in line with previous findings (12). Interestingly, the effect of tolerization was more prominent in females (Fig. 1).

Although lesions of tolerized mice were smaller than those of controls, the structure of the lesions was identical. Lesions were composed of a lipid core surrounded by a fibrous cap (Fig. 1). The cellular composition of the plaque was not altered to any substantial extent by tolerization, as indicated by major histocompatibility (MHC) class II (Fig. 1), CD4, and CD8 immunohistochemistry (not shown).

ApoE KO mice develop a humoral response directed against oxLDL $(6,24)$. In order to determine whether tolerization was affecting the B-cell response, the level of antibodies directed against native LDL, copper-oxidized LDL, and MDA-modified LDL was measured in serum samples. As shown in Table 1, the titers of antibodies against copper-oxidized LDL were increased moderately in both groups, compared with antibodies directed against native LDL (values above 1). Female mice had higher anti-oxLDL IgG titers than male mice. The titers of IgG and IgM directed against MDA-LDL were elevated in both sexes. Although not statistically significant, tolerization tended to decrease the titers of antibodies directed against modified LDL. Although these data do not allow us to rule out an effect of tolerization on the $\mathrm{B}$-cell response, they suggest that the humoral reaction is not the central pathogenic trigger. However, it should be pointed out that oxLDL is not a homogenous antigenic molecule, but a particle with a large number of oxidizable epitopes. It is, therefore, extremely difficult to standardize oxLDL preparations in such a way that the precise quantitative and qualitative properties of antigenic epitopes are preserved between immunogens and assays. This should be kept in mind when evaluating data on oxLDL immunoreactivity.

T-cell proliferative responses were analyzed in cell suspensions of spleen and LN. T cells from control mice were proliferating in a dose-dependent way to oxLDL. As for humoral responses, there was some variability in the responses. Tolerization clearly decreased the proliferative response of $\mathrm{T}$ cells to oxLDL (Fig. 2).

To exclude the possibility that differences in the relative number of $T$ and $B$ cells, or of $\mathrm{CD}^{+}$and $\mathrm{CD}^{+} \mathrm{T}$ cells that could account for the difference observed in the proliferative response, we performed FACS analysis of the main cell populations. As shown in Table 1, tolerization did not change the distribution of the main cell populations. The activation marker CD69 was unaffected by tolerization. These data were corroborated by the fact that the total proliferative response of $\mathrm{T}$ cells to the polyclonal mitogen, ConA, was not changed in the tolerized mice (Fig. 2).

It has been shown that the nature of adjuvants plays a major role in determining the Th1/Th2 balance during neonatal tolerance induction (11). The lack of strong proliferative responses to oxLDL in either the $\mathrm{LN}$ or the spleen could be due to the preparation of the injected tolerogen, such as the absence of adjuvant. This allows us to refute the "immune deviation" hypothesis to explain the state of tolerance in the present experimental model. Thus, as discussed above, the decreased reactivity of $\mathrm{T}$ cells towards oxLDL could be explained either by clonal deletion or anergy. Since stimulation of anergic cells to proliferate with interleukin-2 (IL-2) has been shown to remove the cells from this state $(25,26)$, IL-2 was added to our cell cultures. As shown in Figure 2, addition of IL-2 increased the proliferation of LN cell suspensions from control mice in response to oxLDL. In contrast, addition of IL-2 did not induce LN cells from toler- 


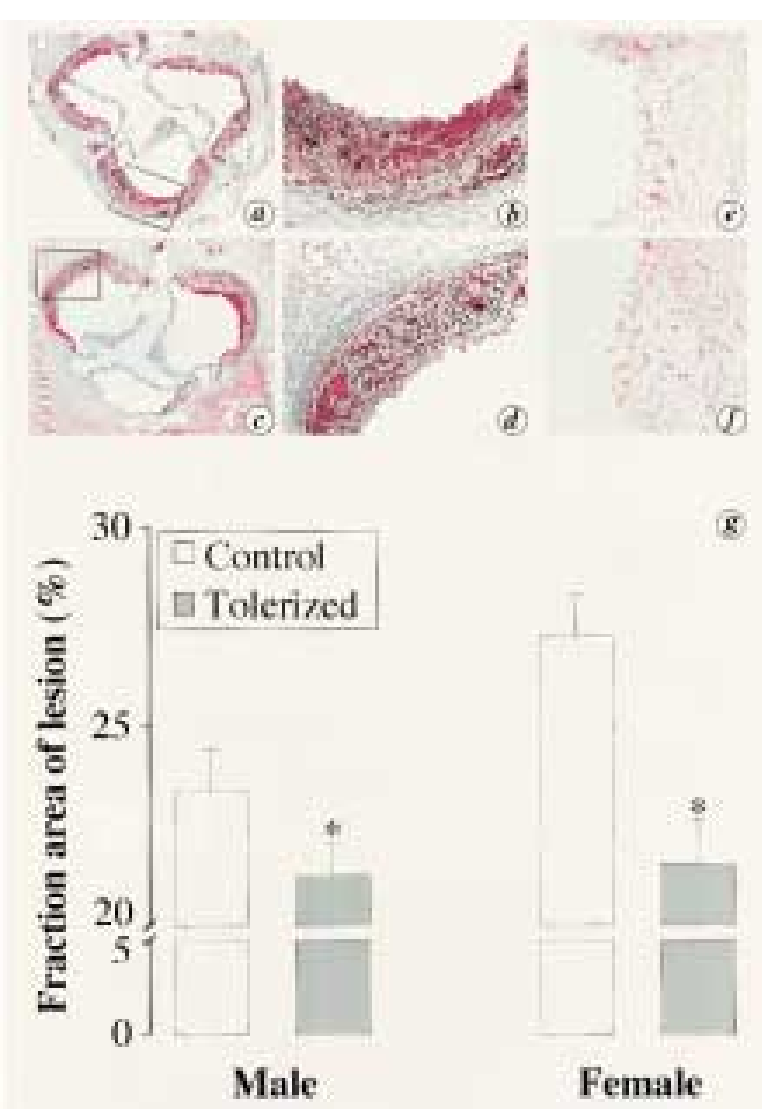

Fig 1. Tolerization reduces the development of atherosclerosis. Control and tolerized apoE knockout (KO) mice were fed a Western diet for 4 months. Aortic root cryosections were either stained for lipids with oil red $\mathrm{O}$ (A,C: magnification $\times 5$; B,D. magnification $\times 20$ ) or immunostained with anti-I-A antibodies (E,F: magnification $\times 20$ ). Fraction area of lesion (lesion surface/vessel surface) was measured on cryosections from the aortic root $(G)$. Means \pm SEM, "significantly different from control group, $p<0.01$.

ized mice to proliferate in response to oxLDL, indicating that tolerization was not achieved by anergy. Equivalent results were obtained with spleen cell suspension (not shown). Cell suspension from control mice and tolerized mice proliferated at the same rate in the presence of ConA, with or without IL-2, implying that tolerization did not result in a general reduction of T-cell proliferative capacity (Figure 2). Together, our data show that neonatal injection tolerizes $T$ cells to oxLDL and reduces atherosclerotic lesions in apoE KO mice.

In order to determine whether tolerance was effectively achieved by clonal deletion of $\mathrm{T}$ cells, a profile analysis of the variable region of the T-cell receptor $\beta$ chain $(\mathrm{V} \beta)$ was performed as previously described $(22,27)$. This method is

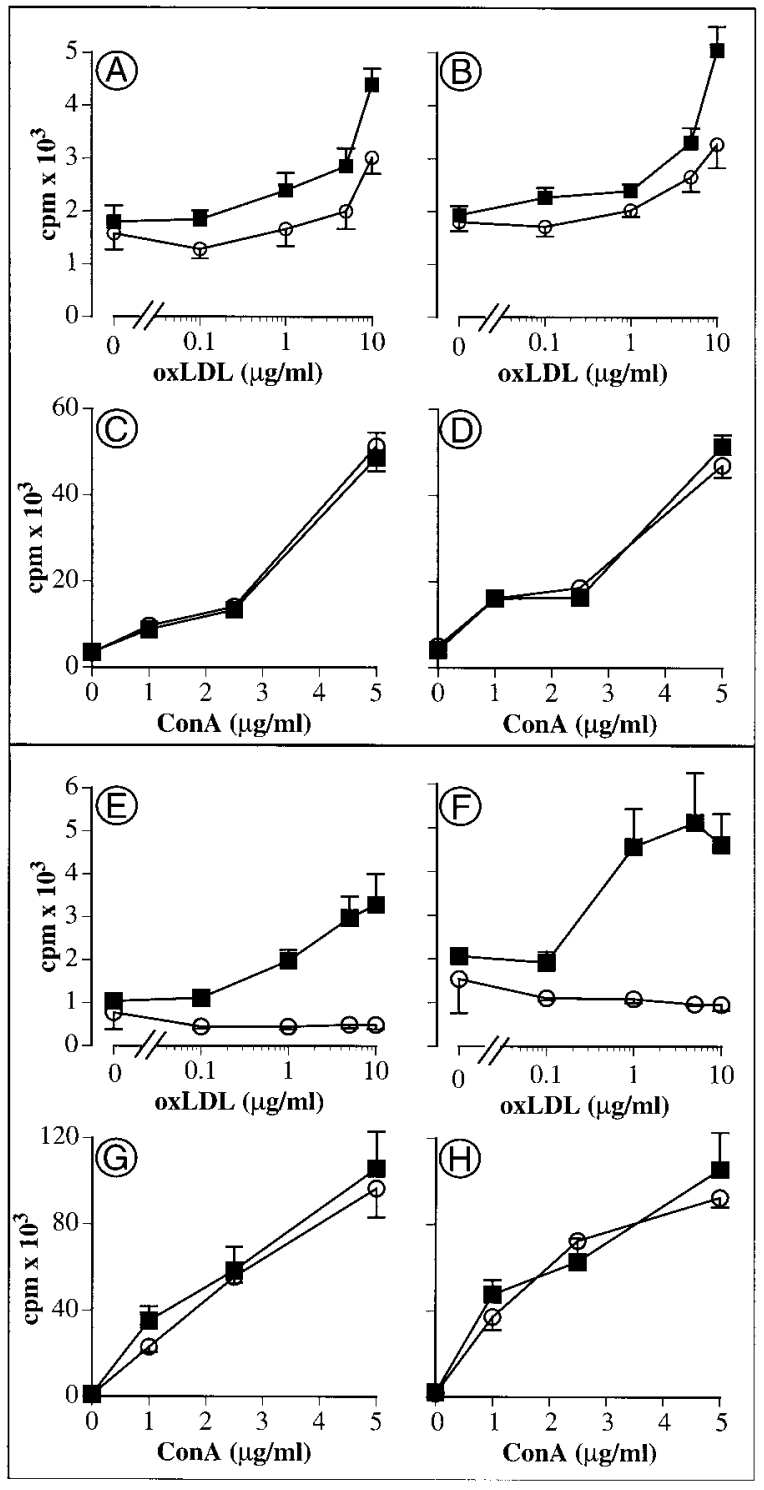

Fig. 2. Injection of oxidized low density lipoproteins (oxLDL) achieves a partial tolerization to oxLDL through clonal deletion rather than anergy. (A-D) The oxLDL (A,B) and concanavalin A (Con A)-induced (C,D) proliferations $\left({ }^{3} \mathrm{H}\right.$-thymidine incorporation, cpm) were analyzed on spleen cell suspensions from male $(A, C)$ or female $(B, D)$ mice. Cell suspensions from tolerized mice ( nificantly lower proliferative response to oxidized LDL than controls ( + ), while exhibiting a similar proliferative response towards Con A. Means \pm SEM, *significantly different from control group, $\mathrm{p}<0.05$. $(\mathrm{E}-\mathrm{H})$ lymph node cells were pooled per group and were cultivated with $(\mathrm{F}, \mathrm{H})$ or without $(\mathrm{E}, \mathrm{G})$ interleukin-2 (IL-2), in addition to oxLDL, or ConA. The addition of IL-2 to cell suspensions from tolerized mice did not alleviate unresponsiveness, indicating that the mechanism involved in the tolerance induction is a clonal deletion. Note that addition of IL-2 to control cell suspensions increased their proliferation to oxLDL. ConA response was unaffected by IL-2 addition in both control and tolerized mouse cell suspensions. Means \pm SEM of triplicate. 


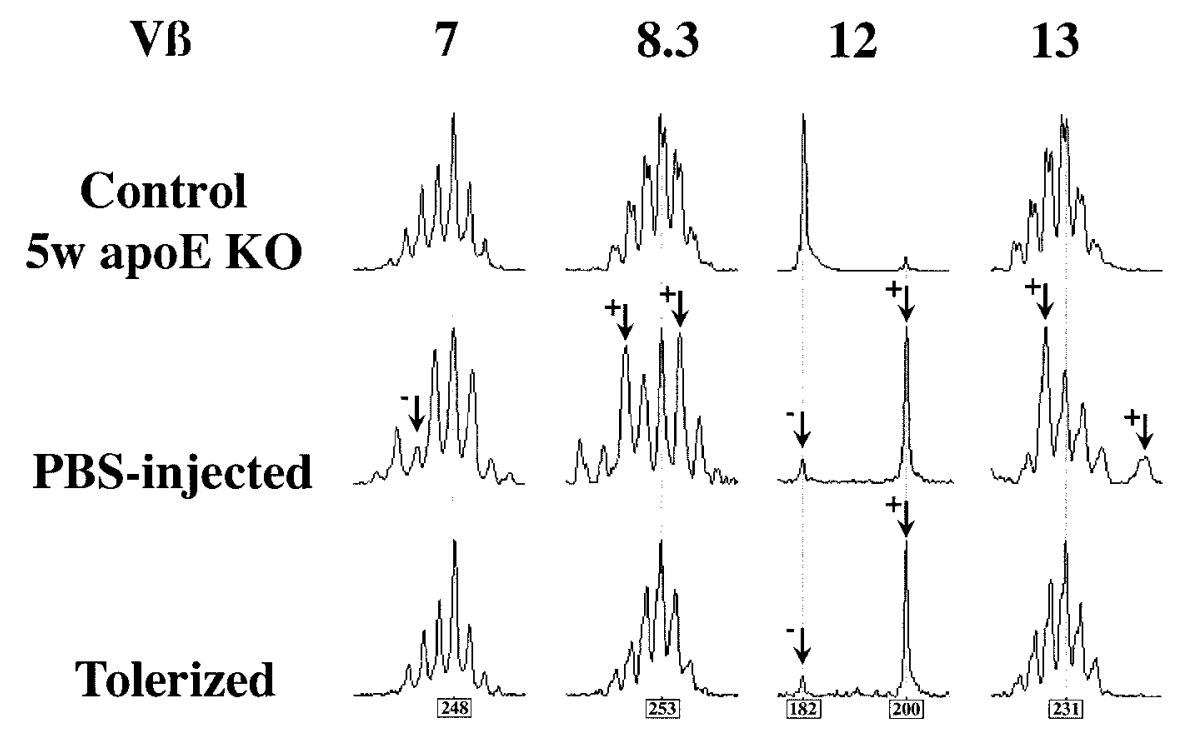

Fig. 3. CDR3 length analysis of the T-cell receptor. The repertoire of the variable region of the $\beta$ chain $(\mathrm{V} \beta)$ in lymph nodes from young nondiseased (5-week-old, top row), phosphate buffered saline (PBS)-treated (middle row), or tolerized (bottom row) 5-month-old apoE knockout (KO) mice. Reverse transcription polymerase chain reaction (RT-PCR) was performed according to "Materials and Methods". The y-axis represents the fluorescent intensity and the $x$-axis the length of the amplified product. The framed values are the lengths (bp) of the PCR products in the major peaks. Observe that for the V $\beta 12$ subfamily, only two populations are detected. In the group of PBSinjected mice, there are skewings of the $\mathrm{V} \beta$ profiles indicated by arrows. $\boldsymbol{\nabla}^{+}$indicates expansions of clones over the Gaussian distribution, $\downarrow \nabla$ indicates decrease or disappearance of T-cell populations. These skewings are less common in the tolerized group. The profile of the $\mathrm{V} \beta 8.3$ and 13 is altered in some mice, but not in the others, indicating that the disease does not recruit always the same clones.

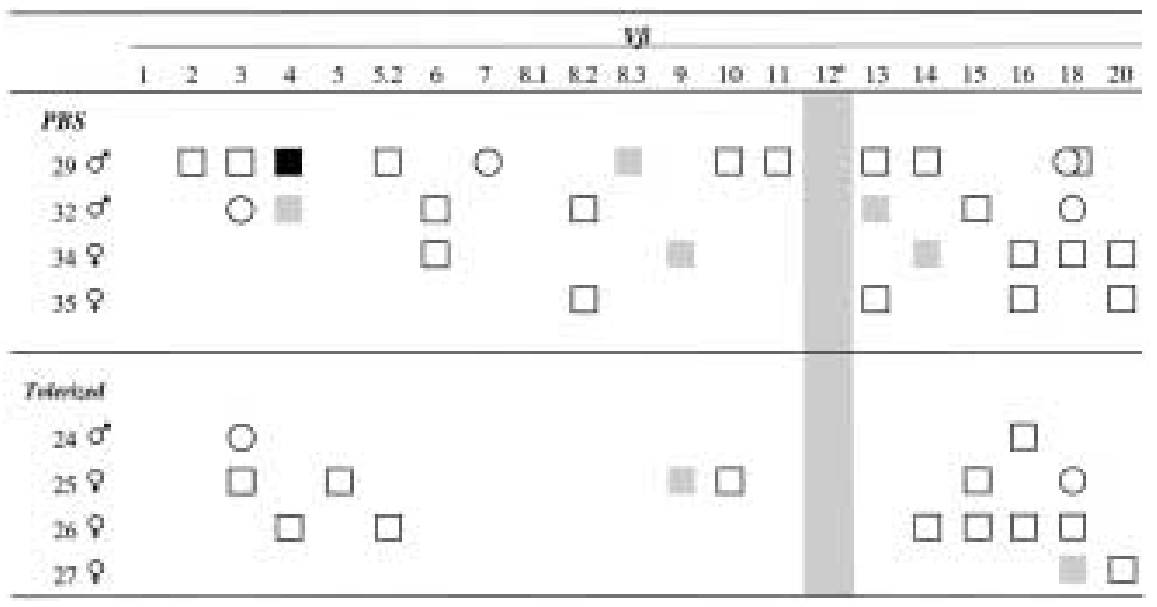

Fig. 4. Tolerization normalizes the T-cell repertoire. Estimate of the $\mathrm{V} \beta$ usage in phosphatebuffered saline (PBS) treated and tolerized mice. Squares represent an expansion of clones, while circles represent deletion of clones in either the spleen or lymph nodes. The colors of the symbols stand for a semi-quantitative assessment of the modification and was determined by two indepen- dent observers. The white symbols are for a moderate modification, the black for an extended modification, and the grey for intermediate modification. For an example of the length analysis profile, see Figure 3. The V $\beta 12$ was presenting an atypical length analysis profile and was analyzed separately (Figure 3). 
based on the fact that nucleotide transferases add or remove nucleotides at the various $\mathrm{V} \beta$ $\mathrm{D} \beta$ and $\mathrm{D} \beta-\mathrm{J} \beta$ junctions (i.e., junctions in the $\beta$ chain transcript between $\mathrm{V} \beta$ and the diversity $(\mathrm{D} \beta)$ and between the $\mathrm{D} \beta$ and the joining $(\mathrm{J} \beta)$ regions) during the recombination process of the T-cell receptor, leading to length variation of the CDR3 region by as many as 6-8 amino acids. Thus, for each $\mathrm{V} \beta$ subfamily, PCR amplification of the CDR3 regions will yield an average of eight peaks spaced by three nucleotides. An increase in peak height usually signals a monoclonal expansion over the polyclonal background (27). On the other hand, deletion of clones can be detected only if a large number of $\mathrm{T}$ cells sharing the same CDR3 length are missing.

Using this approach, we found that although most of the $\mathrm{V} \beta$ subpopulations were distributed along a Gaussian curve, a limited number of clones were expanded and others deleted in the 5-month-old, PBS-injected apoE KO mice, compared with young apoE KO mice that had not yet developed atherosclerosis (Figs. 3 and 4). The $\mathrm{V} \beta$ usage of the expanded/ deleted clones was not the same in all the mice analyzed and the expanded/deleted populations were not always found in both the LN (data not shown) and the spleen, demonstrating that the disease recruited several T-cell clones that differed among animals and that these clones homed differentially in LN and spleen.

The PCR profiles in the tolerized mice corresponded more to those of the young, nonatherosclerotic mice. These results suggest that tolerization led to a normalization of the T-cell repertoire that would otherwise have been altered by the progression of the disease. They also imply that the generation of new epitopes by oxidation of LDL recruits several T-cell clones.

As shown in Figure 3, $\mathrm{V} \beta 12$ subpopulations were not distributed along a Gaussian curve, but in two discrete peaks of 182 and $200 \mathrm{bp}$. In the young, non-atherosclerotic apoE KO mice, the $182 \mathrm{bp}$ population was the only one detected; whereas, both subpopulations were represented in the older mice.

This study shows that induction of neonatal tolerance of apoE KO mice to oxLDL leads to decreased atherosclerosis in adult animals and is associated with a T-cell tolerance to oxLDL. We also demonstrate that the T-cell repertoire of apoE $\mathrm{KO}$ mice is altered during the progression of the disease, but normalized by tolerization. Finally, our data suggest that Tcell tolerance was achieved by clonal deletion, rather than by anergy. These results suggest that the cell-mediated immune response directed against oxLDL plays an aggravating role in atherosclerosis.

\section{Acknowledgment}

We thank Ingrid Törnberg, Kerstin Carlson, Inger Bodin, and Anita Larsson for excellent technical assistance. This work was supported by the Swedish Medical Research Council (proj. 6816) and Heart-Lung Foundation, the Johnson and Wallenberg Foundations, King Gustaf V 80th Anniversary Fund, Tore Nilsson Foundation, and the AFA Research Fund, A. $\mathrm{N}$. was the recipient of a Marie Curie postdoctoral research fellowship from the European Union.

\section{References}

1. Plump AS, Smith JD, Hayek T, et al. (1992). Severe hypercholesterolemia and atherosclerosis in apolipoprotein E-deficient mice created by homologous recombination in ES cells. Cell 71: 343-353.

2. Piedrahita JA, Zhang SH, Hagaman JR, Oliver PM, Maeda N. (1992). Generation of mice carrying a mutant apolipoprotein $\mathrm{E}$ gene inactivated by gene targeting in embryonic stem cells. Proc. Natl. Acad. Sci. U.S.A. 89: 4471-4475.

3. Zhou X, Stemme S, Hansson GK. (1996). Evidence for a local immune response in atherosclerosis. CD4+ $\mathrm{T}$ cells infiltrate lesions of apolipoprotein-E-deficient mice. Am. J. Path. 149: 359-366.

4. Stemme S, Holm J, Hansson GK. (1992). T lymphocytes in human atherosclerotic plaques are memory cells expressing CD45RO and the integrin VLA-1. Arterioscler. Thromb. 12: 206-211.

5. Stemme S, Faber B, Holm J, Wiklund O, Witzum JL, Hansson GK. (1995). T lymphocytes from human atherosclerotic plaques recognize oxidized low density lipoprotein. Proc. Natl. Acad. Sci. U.S.A. 92: 3893-3897.

6. Palinski W, Ord VA, Plump AS, Breslow JL, Steinberg D, Witztum JL. (1994). ApoEdeficient mice are a model of lipoprotein oxidation in atherogenesis. Demonstration of oxidation-specific epitopes in lesions and high titers of autoantibodies to malondialdehydelysine in serum. Arterioscler. Thromb. 14: 605-616.

7. Salonen JT, Ylä-Herttuala S, Yamamoto R, et al. 
(1992). Autoantibody against oxidised LDL and progression of carotid atherosclerosis. Lancet 339: 883-887.

8. Esterbauer H, Ramos P. (1996). Chemistry and pathophysiology of oxidation of LDL. Rev. Physiol. Biochem. Pharmacol. 127: 31-64.

9. Nicoletti A, Caligiuri G, Törnberg I, Kodama T, Stemme S, Hansson GK. (1998). The macrophage scavenger receptor type A directs modified proteins to antigen presentation. Eur. J. Immunol. 28: 1-10.

10. Nicoletti A, Kaveri S, Caligiuri G, Bariety J, Hansson GK. (1998). Immunoglobulin treatment reduces atherosclerosis in apo E knockout mice. J. Clin. Invest. 102: 910-918.

11. Forsthuber T, Yip HC, Lehmann PV. (1996). Induction of $\mathrm{TH} 1$ and $\mathrm{TH} 2$ immunity in neonatal mice. Science 271: 1728-1730.

12. Caligiuri G, Nicoletti A, Zhou X, Tornberg I, Hansson GK. (1999). Effects of sex and age on atherosclerosis and autoimmunity in apoEdeficient mice. Atherosclerosis 145: 301-308.

13. Palinski W, Ylä-Herttuala S, Rosenfeld ME, et al. (1990). Antisera and monoclonal antibodies specific for epitopes generated during oxidative modification of low density lipoprotein. Arteriosclerosis 10: 325-335.

14. Palinski W, Rosenfeld ME, Ylä-Herttuala S, et al. (1989). Low density lipoprotein undergoes oxidative modification in vivo. Proc. Natl. Acad. Sci. U.S.A. 86: 1372-1376.

15. Zhou X, Paulsson G, Stemme S, Hansson GK. (1998). Hypercholesterolemia is associated with a T helper (Th) 1/Th2 switch of the autoimmune response in atherosclerotic apo E-knockout mice. J. Clin. Invest. 101: 1717-1725.

16. Gascoigne NR, Chien Y, Becker DM, Kavaler J, Davis MM. (1984). Genomic organization and sequence of T-cell receptor beta-chain constant- and joining-region genes. Nature 310: 387-391.

17. Patten P, Yokota T, Rothbard J, Chien Y, Arai K, Davis MM. (1984). Structure, expression and divergence of T-cell receptor beta-chain variable regions. Nature 312: 40-46.

18. Barth RK, Kim BS, Lan NC, et al. (1985). The murine T-cell receptor uses a limited repertoire of expressed V beta gene segments. Nature 316: 517-523.

19. Behlke MA, Chou HS, Huppi K, Loh DY. (1986). Murine T-cell receptor mutants with deletions of beta-chain variable region genes. Proc. Natl. Acad. Sci. U.S.A. 83: 767-771.

20. Chou HS, Anderson SJ, Louie MC, et al. (1987). Tandem linkage and unusual RNA splicing of the T-cell receptor beta-chain variable-region genes. Proc. Natl. Acad. Sci. U.S.A. 84: 1992-1996.

21. Louie MC, Nelson CA, Loh DY. (1989). Identification and characterization of new murine $\mathrm{T}$ cell receptor beta chain variable region (V beta) genes. J. Exp. Med. 170: 1987-1998.

22. Pannetier C, Cochet M, Darche S, Casrouge A, Zoller M, Kourilsky P. (1993). The sizes of the CDR3 hypervariable regions of the murine $\mathrm{T}$ cell receptor beta chains vary as a function of the recombined germ-line segments. Proc. Natl. Acad. Sci. U.S.A. 90: 4319-4323.

23. Koide Y, Kaidoh T, Yanagawa T, Yoshida TO. (1993). A comparative study on $T$ cell receptor V beta gene usages: spleen cells from the nonobese diabetic (NOD) mouse and its nondiabetic sister strain, the ILI mouse, and infiltrating $\mathrm{T}$ cells into pancreata of NOD mice. Microbiol. Immunol. 37: 653-659.

24. Palinski W, Hörkkö S, Miller E, et al. (1996). Cloning of monoclonal autoantibodies to epitopes of oxidized lipoproteins from apolipoprotein E-deficient mice. Demonstration of epitopes of oxidized low density lipoprotein in human plasma. J. Clin. Invest. 98: 800-814.

25. Beverly B, Kang SM, Lenardo MJ, Schwartz RH. (1992). Reversal of in vitro T cell clonal anergy by IL-2 stimulation. Int. Immunol. 4: 661-671.

26. Essery G, Feldmann M, Lamb JR. (1988). Interleukin-2 can prevent and reverse antigeninduced unresponsiveness in cloned human $\mathrm{T}$ lymphocytes. Immunology 64: 413-417.

27. Pannetier C, Even J, Kourilsky P. (1995). T-cell repertoire diversity and clonal expansions in normal and clinical samples. Immunol. Today 16: 176-181. 